\title{
Enkele Gedagtes oor die Nuwe Teologie soos beoefen deur Gereformeerde Teoloë
}

\section{INI.EIDEND.}

Die onderwerp. soos geformuleer. is reeds in stelling waardeur die koers aangedui word waarin die gereformeerde teologie beweeg; veral onder leiding van Nederlandse teoloë verbonde aan die V.l l. van AmsterJam en die Theologische Hogeschool te Kampen. Op die oog af hou die stelling 'n kontradiksie in. Die benaming nuwe teologie word immers gebruik vir die eksistensialistiese teologie. En uit voordragte van dr. J. Postma, ds. P. (j. I. v. d. Walt en dr. V. E. d'Assonville het dit reeds duidelik geword dat hierdie nuwe teologie moet uitloop op totale godloëning: op die God-is-dood-kreet! Daarteenoor het dit nog altyd in die geref, teologie gegaan oor die kennis aangaande God soos dit tot ons kom in sy Selfopenbaring deur Sy Woord en werke. (vgl. Art. II V. N.G.B.) Soos ons die tradisionele geref. teologie ken, veral soos dit in dic dogmatick kulmineer, gaan dit vir die gereformeerde teoloog om die kennis van die lewende God soos $\mathrm{Hy}$ Homself openbaar en Sy verhouding tot die Skepping met die mens aan die hoof daarvan: " $n$ verhouding waarin die eer van (jod voorop staan en gehandhaaf word deur gerig en genade heen. Daar kan dus geen werklike aanrakingsvlakke wees tussen die nuwe teologie. wat wesenlik antropologie is. en die gereformeerde teologie nie. En tog word hierdie aanrakingsvlakke vandag gesoek en gevind deur teoloë wat nog gereformeerd wil wees soos dr. H. M. Kuitert en wat ek sy skool wil noem. Daar moet egter opgemerk word dat Lever met sy ..Creatie en Evolutie" die eintlike stoot aan die rigting gegee het. Hy het gedwing tot die soek na "n nuwe hermeneutiek onder die gesag van die natuurwetenskappe. Kuitert kies doelbewus 'n ..eigen weg" ('n term wat vir hom geskikter is as ..derde weg") vir die teologie. M.a.w. nog die nuwe teologie. nog die tradisionele gereformeerde teologie bevredig hom. Daar is sowel in die eksistensiale interpretasie as in die metafisiese teologie (hieronder word veral ook die geref. teologie gereken) beide clemente wat tot die onvervreemdbare .eeigene" van die teologie behoort. (De Realiteit van het (jeloof. p. 156). Die eie of derde weg bestaan dan daarin dat 'n teologie ontwikkel word wat aan die waarheids-elemente van beide die cksistensieteologie en die geref. teologie reg laat geskied. Op sy beste kan ons dan in sinkretisliese teologie verwag wal poog on die waarheidselemente in beide te verenig. (Ons het so te doen met in poging deur geref. teoloé on die kontradiksie in my aanvangstelling op te hef. Die resultaat van die poging, so sal ek probeer atantoon, is dan dat die weg tot kapitulasie voor die nuwe eksistensialistiese teologie nie not voorberei is nie maar dat op groot skaal begin is on die geref. teologie te laat inpas by die nuwe teologic. Sinhretisme loop altyd uit op in oorwinning vir die slegste element van die elemente wat versoen moet word! 
Vooraf stel ek net dat daar al veel in Nederlandse geref. kringe reds sedert Lever se ..Creatie en Evolutie" oor dic ontwikkeling gedebatteer en gepolemiseer is - vragenderwys is dit deur sommige gereformeerdes gestel of dit daarin nie gaan on "n ,.koerswysiging" nie. Ander, veral uit die kringe van die Vrygemaakte Geref. Kerke het sekere beskouinge van die skool van Kuitert bestempel as soveel bewyse dat dic gereformeerde teologie ingeruil is vir die nuwe. "n Omvaltende beoordeling van die nuwe ontwikkeling tot op die hede kan bestaan. maar is my nog nie bekend nie. Daarom is dit vir my eintlik 'n waagstuk on die stelling te maak dat die geref. teoloc inderdaad besig is om dic nuwe teologie te beofen. Tog doen ek dit om u te prikkel tot besinning oor die gevare wat hierdie ontwikkeling ook vir ons inhou. Vit dic aard van die saak kan u nie 'n afgeronde en wetenskaplik-onaanvegbare studic van my verwag nie. Daarvoor is diz onderwerp te omvattend en is manne nodig met 'n grondiger kennis as wat ek het. Tog meen ek dat ek deur die uitspreek van enkele gedagtes grondig genoeg sal kan aantoon dat ons inderdaad te doen het met ..die nuwe teologie soos beoefen deur gereformeerde teoloe”.

\section{DIE NIIWE TEOI.OGIE.}

Ek sal u nie vermoei met in bree uiteensetting van die nuwe teologie nie - dit is voorheen reeds gedoen. Dit is egter nodig om ter herinnering weer die aandag op die hoofsaak te vestig. Sanievattend is die kenmerk van die nuwe teologie, volgens Kuitert, in die ontwikkeling daarvan antimetafisies gerig. Dit gaan in die dogmatiek nie meer on objektiewe uitsprake nie, maar wel om die persoonlike geloofskonklusies (a.w.p. p. I()).

Hierdie antimetafiese tendens kom by die eksistensie-teologie na vore in die radikale afrekening met die objektiewe waarhede. Die moJerne denke word totaal beheers deur die kausaliteits-beginsel. wat die natuurwetenskap na vore gebring het. Ons het te doen met 'n geslote wèreld ..waar zelfs God zijn vingers - als wij ons zo plastisch mogen uitdrukken -- niet meer tussen schijnt te krijgen" (a.w.p. p. 12).

Die metafisiese teologie werk met objektief-vasstaande waarhede waarvan die Heilige Skrif die onfeilbare bron is. Ciol hel geopenbaar wat waarheid is en geloof is dan die kennis en die vir-waar-hou van hierdie objektief-vasstaande waarheid. Die nuwe teologie breek met hierdie objektiwiteit. Die realiteit van die geloof is nie gelee in die kennis en vir-waar-hou van die geopenbaarde waarheid nie, maar wel in wat die mens as waarheid ervaar en danvaar. Die mens staan in die sentrum en is die maatstaf waaraan die realiteit van die geloof gemeet word. Waarheid is eers waarheid as dit subjektief vasstaan. Waarheid is nie objektiefvasstaande. ongeag of dit aanvaar word of nie. Waarheid is alleen wat vir jou persoonlik waar is en hoef nie vir 'n ander waar te wees nie. Die antimetafisiese tendens in die teologie is juis ' $n$ verset teen die pretensie dat die teologie besig is met begrippe en voorstellinge wat nie alleen sin het vir die gelowiges wat van hierdie begrippe en voorstellinge gebruik maak nie. matar ook vir ander gelowiges en vir dic 
hele mensheid (vgl. Kuitert a.w. p. 23).

Die ortodoksic laat die geloof die aksent kry van: die-vir-waarhou van die veritates van die theologia revelata. Die teologie is Jan die wetenskaplike apparaat wat die veritates tot so 'n logies moontlik geheel verwerk. En aan hierdie teologie lê die aristoteliese filosofic ten grondslag (vgl. a.w. p.p. 24/5).

Hier noet opgemerk word dat indien kuitert nie 'n karikatuurbeeld van die ortodokse (vir hom ook geref.) teologie gee nie. dit tenminste eensydig genoem moet word. In sy werke ..De Realiteit van het geloof" en ..De Mensvormigheid (jods" is dit juis opvallend dat hy geen onder. skeid maak tussen die gereformeerde teologie en afwykinge daarvan nie. Hy vat die hele teologiese ontwikkeling saam onder die term ortodoksie. Die lyn word gemaklik deurgetrek veral in die eerste deel van ..De Mensvormigheid Cods". vanaf Philo oor Origenes to by Kuyper Bavinck en Schilder. Wat die geloof betref word die kennis en vir-waarhou van die openbaring deur Kuitert in sy weergawe van die ortodokse standpunt oorgeaksentueer ten koste van uie vertroue. Daarom laat hy ook die ortodoksie opgaan in dorre skolastisisme. Die ortodoksie het verval in "n dorre. lewensvreende objektivisme. Geloof by die ortodoksie is dan bloot vir hom die-vir-waarhou-van objektief vasstaande geopenbaarde waarheale. Hierdie karikatuuragtige weergawe wat hulle van die ortolokse geref. leer oor geloof gee. ten spyte van o.a. die kernagtige geref. belydenis vervat in Sondag VII van die Kategismus. is hoofsalaklik die rede waarom Kuitert en sy skool hulle gedwonge ag om in cie weg te gaan in die ontwikkeling van die teologie.

Dit gee die aanleiding dat hy die antimetafisiese tendens in die teologie regverdig. Die antimetafisiese tendens is dan ook kenmerk van die teologie van kuitert en sy skool. Die ortodokse teologie met sy aristotelies-metafisiese karakter is ..agterhaald" en die weg terug is onmoontlik. Die voor-veronderstelling vir die funksionering van die tradisionele metafisika het uit die moderne lewensklimaat verdwyn. Daarby het die swerftog van die moderne teologie nie sonder vrugte gebly nie (vgl. Kuitert. De Realiteit van het geloof. p.152). Die cerste gemeenskaplike vlak waarop hierdie geref. teolö̈ die beofenaars van die nuwe- (eksistensie) teologie ontmoet, is dus die antimetafisiese gerigtheid van hulle teologie.

\section{DII: HERMENEUITIEK EN DIE NUWE TEOLOGIE}

Hierdie gemeenskaplike front teen die metafisiese ortodoksie duing Kuitert en sy stiool om ook by die nuwe teologie lig te soek op dic terrein van die hermeneutick. Die hulp van die hermeneutiek word ingeroep ter verantwoording van dic antimetafisiese tendens (vgl. Kuitert a.w. p. 37). Dic dogmatick ontvang so in spesificke sin $n$ hermeneutiese spits (Kuitert: De Mensvormigheid (iods p.p. 8 en 9). (Ou posisies moet verlaat word on nuwes te betrek. Vir Kuitert in teestelling met die eksistensialiste moet die eksegese wel nog deur die dognatiek gekon. troleer word. maar die dogma moel deur die eksegese geverifieer woral. Dit hou vir hom in gevaarlihe sirhelgang in. Die dogma is "n hermeneu. 
liese prinsipe by die éksegese en so word vanuit die dogna gecksegetiseer; terwyl die eksegese aan die ander kant die dogma moet bewys. Daarom moet die nuwe teologie. waar dit afstand doen van die ouc, rekening hou met die dogma as hermeneutiese prinsipe in die eksegese en tegelyk die prinsipe "n ander inhoud gee. Hier dreig "n ander gevaar. Die eksegese kan in die proses willekeurig word. Kuitert los die probleem vir homself op deur 'n kritiese toetsing van die dogma as hermeneutiese prinsipe in die lig van die teks wat moet geëksegetiseer word. Die vraag waarvoor die teoloog dan te staan kom is: Is die hermeneutiese prinsipe - d.i. die spesifieke dogma - van die waaruit die teks gelees is, vir sy taak as kriterium bereken of is hierdie geskiktheid by nader insien slegs skynbaar? So is dogmatiese vrae tegelyk ook hermeneutiese vrac. Sowel in die Jogmatiek as in die hermeneutiek gaan dit om die verstaan van die Heilige Skrif met die oog op die prediking. Dogmatiek kan dan kritiese hermeneutiek genoem word (vgl. De Mensvormigheid Gods. p. 9 en noot 25). Hieruit meen ek af te lei dat Kuitert stilweg die ou uitgangspunt dat die dogma vas is tensy die teëdeel bewys word. laat vaar het. Dit moet steeds deur die eksegeet as verdag beskou word - hy moet steeds vra is die dogma vir sy taak as kriterium bereken? Die nuwe teologie - eksistensie-teologic .. breek openlik met die dogma en gaan biblisisties te werk. Op hulle .,eie weg" is Kuitert en sy skool nog besorgd oor die dogma en wil dit in ere hou, maar behou tog die reg voor on die dogma altyd krities te benader en kon so ook maar op die biblisistiese spoor. om. bv. in ..De Mensvormigheid Gods". tot konklusies te kom wat eintlik "n streep deur artt. I-V van die N.G.B. trek. (Dit sou ons te ver voer om hierop nader in te gaan. Later sil by wyse van voorbeeld weer hierop teruggekom word.)

Om die nuwe hermeneutiese uitgangspunt van Kuitert en sy skool in perspektief te sien is nodig om eers na te gaan wat hermeneutiek vir die eksistensie-teologie is. Bultman word as voorbeeld geneem -. (hoewel Ebeling en Fuchs o.a. by die nades uitwerking van hom verskil. is hulle opvattinge wesenlik een). Hermeneutiek behandel die reëls van uitlegging vir die teks. Vir die eksistensialiste is dit die eksisientiale interpretasie wat voer tot die eksistentiële verstaan (of ..ter tale" bring). wat pas kan as die teks my daadwerklik in my menssyn raak. (Om " $n$ historiese teks te verstaan. moet daar 'n lewensbetrekking lussen ons en die teks wees. Die historiese teks moet vir ons iets aktueels word. Van aktualiteit of 'n lewensbetrekking is daar egter eers sprake as ons eintlike menssyn in geding kom. Alle mense het een, gemeenskaplike. interesse ook met die wat voor ons geleef het en dit is die interesse in die eie menswees. ' $n$ Mens kan aandag he vir baie dinge. maar moet aandag hê vir homself en vir dic wyse waarop hy mens is. Hierdie aandag vir myself en die wyse waarop ek mens is. verbind my met dic outeurs van geskrifte uit die verlede. Dus: vir sover die teks my menssyn raak, kan ek dic teks verstaan (vgl. Kuitert. De realiteit van het Geloof. p. 43). Van verstaan is dus eers sprake as die teks aan my iets doen - my anders maak. Ek verstaan dic teks eers as dit my uitlok tot 'n nuwe daad van selfbevestiging. tot 'n nuwe daad walarin ek die verantwoordelikheid vir myself op myself ncem en durf neem. Dic 
waarheid van dic teks van dic Heilige Skrif hang af van die aktucle toepassingsmoontlikheid daarvan (vgl. a.w. p. 76). In die Skrif is mense aan die woord. Daarom gaan dit nie vir ons in die Heilige Skrif om die skrywers se voorstellingswêreld of om hulle neiging om alles vir histories uit te gee wat vir ons vandag apokrief voorkom nic. Tot die sauk moet deurgedring word; naamlik die ervaring van of ontmoeting met Cod in sy selfopenbaring. Van (jod kan ons slegs sî̀ wat Hy aan ons doen of welke ervaring $\mathrm{Hy}$ vir ons in ons menssyn beteken. In ooreenstemming met die grondreäl het ons die Heilige Skrif eers verstaan as ons sien wat die selfopenbaring van Cod vir die skrywers beteken het. Hulle getuienis is omskrywing van selfinterpretasie. So bly die heilsboodskap nie in leë woord nie, maar een wat aan ons iets doen. Dit kan alleen as die skrifverhale en voorstellingswêreld in in reeks ervaringe van menssyn. wat daaruit gekristalliseer is. omgesit word. Daarom moet ontmitologisering op die Heilige Skrif tocgepos word. Die skrywer druk hulle uit as kinders van die tyd. Al hulle voorstellings kan nie vir-waar-gehou word nie. Die historisiteit van die verhale is van geen belang van eksistenticle aard nie. Wat die historiese wetenskap deur die kritiese metode van die verhale oorlaat is onbelangrik. solank altans die dut van Jesus se bestaan en kruisdood nie aangetas word nie. Aan meer houvas in die geskiedenis het die geloof geen behoefte nie. Dit gaan net om Jesus se betekenis vir die geloof.

Deur die gebruikmaking van die eksistensiële interpretasie wil die nuwe teologie die subjektiwiteit tot sy reg laat kom. Hoewel die antimetafisiese tendens in die teologie regtens, vir Kuitert. as agtergrond het die stryd om die goeie reg van die subjektiwiteit teenoor die objektiwiteit. loop dit vir hom in die eksistensie-teologie uit op die totale verdringing van die objektiwiteit deur die subjektiwiteit. God -. met sy vasstaande, geopenbaarde waarhede - word in die leologie verdring deur die mens met sy ervaring en aanvaarding. met sy self-interpretasie - as die enigste maatstaf vir die waarheid. God word in die verhouding (jod en mens geëlimineer. Var 'n verhouding is daar nie meer sprake nie. hoogstens van in konkurrensie tussen Giod en mens. Gol - as hy werklik is ... is daar ten nadele van die mens. Die mens - en hy is werklik, as van werklike menssyn gespreek word - is daar op koste van Gol en sy eer. Beide sluit mekaar uit in so in verhouding na mate die subjektiewe of objektiewe pool benadruk word. In so in verhouding kan (jod nie werklik God en die mens nie werklik mens wees nie (vgl. a.w. p.p. 156/7).

Die fout van die nuwe teologie in die reaksie teen die metafisiese teologie is vir Kuitert nou dat gewerk word met die teëstelling subjektiwiteit-objektiwiteit. Hy wil juis hierdie spanning tussen objektiuiteit en subjektiwiteit in die teologie ontkom. Juis hierdie spanning is die oorsaak dat die metafisiese teologie teen wil en lank verval het in strakke objektivisme: in blote rasionele vir-waarhou van wat geopenbaar is. en die eksistensialistiese teologie weer in 'n strakke subjektivisme: wat uilloop op Goulloining! 
Daarom moet van die skema objekliwiteit-subjekliwiteit losgekom word. Die moderne subjektiwiteit in die teologie mag nic bestry word deur die objektiwiteit daar teenoor te stel nie. On uit die visieuse sirkel van objektiwiteit - subjektiwiteil te breek moet die dogmatiek nou begin by die tradisie in die sin van oorgelewerde geloofigoed. Daarmee kies Kuitert vir hom en sy skool op ..die eigen weg" 'n nuwe hermeneutiese uitgangspunt; die grondvraag is nie wat kan ek verstaan nie. maar: wat is die sin en strekking van die aan alle besinning en eksis. tensie voorafgaande oorgelewerde geloofsgoed. wat die Christelike kerh meegekry het op sy $\operatorname{tog}$ deur die eeue heen (a.w. p. 159). Hy wil nie spreek van Kanon nie. want daaraan sit juis die vraagstuk van die gesag van die Heilige Skrif vas wat in geding is. Die bybelse getuienis is die tradisie. Die bybelse getuienis is die oorgelewerde geloofsgoed.

Met hierdie prysgawe -- of tenminste neutraalstelling -- van die gesag van die Heilige Skrif in die stellingname teen die nuwe teologie het Kuitert homself in die hande van die teëstanders gestel. Die vasstaande. objektiewe waarheid dat die bybel die woord van (jod is laat hy op sy .eeigene weg" los en kom so teen wil en dank op die weg van die nuwe teologie. Die bybel is nie meer gesagsvolle openbaringsbron nie. maar wel bron van die tradisie -. van die oorgelewerde geloofsgoed wat die kerk meegekry het op sy $\log$ deur die eeue heen. Die bybel is die getuienis van die skrywers se ervaring in hulle omgang met Ciod. Dit is die getuienis van wat waarheid vir die bybelskrywers is. Daarom het ons in die O.T. te doen met die oorlewering van die ervaring van die Israeliet met sy Bondgenoot God. Kuitert wys dan ook daarop dat. met betrekking tot die Ciodsbegrip. 'n spekulatiewe wesensbepaling buite die gesigskring van die bybelskrywers gelê het. Daar moet m.i. hier gelet kord op hierdie beklemtoning van die ..gesigskring van die skrywers". Daarin kry ons te doen met die fyn wending in Kuitert se skrifbeskouing. Hy het daarmee teen wil en dank gebreek met die beskouing dat die Heilige Skrif die Woord van (jod is; dit gaan ook vir hom nie meer in die Heilige Skrif om openbaring soos ons dit verstaan nie bekendmaking deur die Heilige Gees nie - maar om de gesigskring. insig. ervaring van die skrywers. Vandaar dan ook sy konklusic dat: (I) Die Heilige Skrif geen spiritualis dei (in die sin van 'n onstoflike wese) leer of veronderstel nie; (2) .,de mensvormigineid (iods in de H.S. doorgaans zijn lichamelijkheid mee veronderstelt of zelfs explisiet uitspreekt" (D) Mensvormigheid (jods. p. 199). L ater probeer hy die stelling wel versag. (p.p. 215 e.v.) as hy op die vraag ingaan wat die mensvormigheid vir die bybelskrywers inhou. Hy handhaaf hocwel dit vir my lyk asof hy homself telkens weerspreek - hierdie stelling dan log weer in so in mate dat sy eindkonklusie kan wees dat die bybelskrywers van die mensvormigheid van (jod spreek omdat die mens beeld van (iod is. I) an is God nie antropomorf - eintlik Hebreomorf nie, maar die mens theomorf (a.w. p. 277/8). Dit is so omdat: .. Niet de beschouwer spreekt maar de belijuler, die in het geen hij over (jod meedeelt zijn deelname aan de bondgenootschappelijke omgang uitdrukt. (iol in zijn spreken en handelen met Israel word door Isruel beleden" (a.w. p. 292). (Ons moet daarop let dat Kuitert daarop nadruk lè dat dit in die ().I. gaan 
om lsraels God in sy ..Bondenoot-zijn" met lsruel. Die Heilige Skrif is dic oorlewering van die Israelict van sy belewing van hierdie Bondgenoot-zijn. Kuitert kan dan verder konkludeer dat dit in die O.T. nie ..on God in die algemeen" gaan nie. maar om lsruels (iod soos Hy deur lsruel beskou. getipeer of onderskei is (a.w. p. 284 en 290)).

In navolging van Kuitert is die Evangelies dan ook vir Baarda (De Betrouwbaarheid van de Evangelien) die oorlewering van die eerste gemeentes van wat Jesus vir hulle is na die opstanding en nie 'n outoritatiewe oorlewering van die apostels nie. Dieselfde opvatting word teruggevind by J. L. Koole (Verhaal en Feit in het O.T.). Die ontstaan van die O.T. is aan die historiese besef van Israel te danke. Die verlede moet aan die vergetelheid ontruk word (vgl. Koole, a.w.. p.p. 19 e.v.). Die kunstenaar gee in die ().T. sy beoordeling van die geskiedenis en spreek sy verlangens uit (vgl. a.w. p. 4()).

Ook Hartvelt (Over Schrift en Inspirasie) sê dat wat ons o.a. van die twee skeppingsverhale in Gen. 1 en 2 vind, die vrug is van die werk van tallose generasies, .. die elk op hun beurt weer vanuit hun omgang met (jod en de ervaring van zijn tegenwoordigheid deze verlalen hebben door verteld, ze hebben toegespits op de eigen situatie en met deze verhalen van het handelen (jods in je geschiedenis van hun volk getuigd hebben van hun vertrouwen op deze (jod in de hem omringende wêreld" (a.w. p. 29). Die Heilige Skrif lè so geen getuienis af van God sonder meer vir Kuitert en sy skool nie. maar van God soos $\mathrm{Hy}$ deur Israel en die gemeente geken is. Die Heilige Skrif iv dan subjektief-Israelities en nic openbaring-Heilige en Goddelike Geskrifte" met die Heilige Gees as outeur nie.".

Ook vir Kuitert en sy skool loop die poging om die spanning in dic teëstelling objektiwiteit-subjektiwiteit te ontkon uit op $n$ oorwinning vir die subjektiwiteit. Daar is nog sprake van God en sy selfopenbaring wat dit ook al beteken - maar wal ons in die tradisie - i.e. die H.S. het, is niks meer as die ervaring van die skrywers nie. Die O.T. is subjektief Israelities. Die N.T. -Evangelies is neerslag van gemeenteteologie; dit is die vertolking of vertaling van Jesus se woorde, die rekreasie daarvan en selfs is aan Hom woordc toegedig wat Hy nie gespreek het nie (vgl. Baurda p. 64).

Reeds in die vaarwaters van die nuwe teologie moet kuitert ook dic volgende skof op die weg meegaan -.. die van die historiese kritiek. Die toepassing van die historiese kritiek op die H.S. is eintlik noodsaak. Tradisie moet histories krities ondcrsoek word. Indien die H.S. nie histories krities ondersoek word nie, sou die teologie geen wetenskap meer wees nie. Die vraag wat krities beantwoord moet word is (1) of die tradisie waur is en (2) wat kan die tradisie vir my beteken? Of selfs: kan 'n tradisie 'n oorlewering uit die verlede - my aangaan? Art. V van die N.C.B. word so losgelaat. Die selfgetuienis van die H.S. word opsy geskuif en die kritiese reale sal nou bepaal wat waar en aktueel is. In die kritiese beantwoording van die vrae is daar vir kuitert nog die voorbehoud dat unieke situasies nie vir onmoontlik verklaar mag word vanwei die unickheid daarvan nie (De Realiteit van het geloof. p. 161/2). Balarda gaan verder en verklaar die N.T. summier as 
histories onbetroubaar, terwyl Koole groot agting vir die wetenshap het wat dwing tot 'n nuwe skrifverklaring om uit die verleentheid te kom waarin teëstrydighede in die H.S. ons bring (vgl. Koole a.w. p. 42). (Ook Th. Delleman - soos ander medewerkers aan die verklaring van dic Kategismus - swig voor die wetenskap en die historiese kritick in sy verklaring van Sondag III. H. Kategismus (Alles in Hom). Nadat hy die evolusieteorie as in ooreenstemming met die H.S. verklaar het (p. 69) gaan hy voort om kragtens die bevinding van die historiese kritiek. die oorsprong van die eerste hoofstukke van (jenesis ten tyde van Dawid te stel. Dit verklaar die feit dat die skeppingsverhaal uitloop op die Sabbat. Die skeppingsverhaal is geskryf vanuit die verbond met Abraham omdat Israel in die tyd van Dawid uit dié verbond geleef het. Daarom maak die verhaal gebruik van die Jooklse week en sy dae wat met sonsondergang begin (vgl. a.w. p.p. 74/7). Die sondeval bied 'n voorbeeld van hoedat die skrywers in die O.T. gebruik gemaak het van die mites van hulle tyd en daar 'n eic inhoud aan gee (a.w. p. 8(1). Ek volstaan met nog een voorbeeld: Op p.p. $81 / 2$ herlei Delleman dic skepping van die vrou uit die rib van Adam (Adam. wat terloops niks anders beteken as ..wij mensen" nie) tot die mite waarin Zcus dic jonkvrou-jongeling in twee splyt. Die ribverhaal is in duidelik herinnering aan 'n verhaal soos die van Zeus: Dit dui op die verhouding man-vrou as ..oorspronkelijk één willen zijn".

Hierdie verklaringsmetode -- wat vanselfsprekend toegepas word deur die eksegete in die nuwe kategismusverklaring vloei voort uit die nuwe hermeneutiese uitgangspunt dat die Heilige Skrif die tradisic is, oorlewering deur mense. Die histories-kritiese metole is nodig omdat die tradisie histories ontstaan het en daarom histories verpak is. Daaraan sit vrae betreffende die wêreldbeeld. kulturele konteks. en historiese bepaaldheid vas. Die saak moet uit die historiese klankbodem gelig word.

Hierdie historiese bepaaldheid raak nie alleen die bybel nic. ook die geloofsbelydenis van die Christelike kerk. Daarom sal die kennis van God altyd meer net histories geformuleer en formuleerbaar wees. Dic Christelike waarheid is dan in die historiese bestaanswyse van die mens gefundeer: ondat die mens histories leef, is daar oorlewering van generasie tot generasie en elke generasie moet die waarheid weer oorformuleer na die eis van sy tyd. Die belydenis is altyil ..on-af".

Hoewel Kuitert dit nog nie openlik sê in die aangehaalde werke nie. vloei hieruit voort dat die belydenisskrifte meer en meer as historiese dokumente beskou word. wat eintlik vandag nie meer deug nic Die remonstrantse revisiebeginsel is dan die juiste i.o.v. dic belydenis. skrifte. Die resultaat van die beskouing vinci ons in die nuwe Kategisnusverklaring. soos hierbo 'n voorbeeld van gegee die oorspronklike vrae en antwoorde kom heel dikwels maar gehawend anderkant uit!

Naas die historiese fundering van die tradisie is daal egter 'n tweede daadkragtiger fundering: ..nl, dat ( $j o x l$ self in sy selfopenbaring hierdic historisiteit van die waarheid oproep en effectueer" (Kuitert: De reali. teit van het geloof p. 16(1). 
Wie die openbaring tydloos sien en nie die Israelitiese karakter daarvan honoreer nie. dwing dic mens van vandag on homself te argaiseer tot 'n kultuurstadium van 2 tot 3 duisend jaar gelede. Ons moet dan weer Israeliele word. Die universele heerskappy van God word ook so misken en Israels God word tot 'n God gemaak wat alleen oor die joodse volk is. Wie die tydsgebondenheid van ons menslike formuleringe misken. misken die eie menslike beperktheid en ken aan sy menslike formuleringe ewigheidswaarde toe. (I.et daarop: dit gaan hier oor dic Skrif - die tradisie - in die eerste plek.) So word ook die trinita. riese wyse waarop God God is misken en word Hy in selfopenbaring in dic verlede opgesluit. Die feit word geëlimineer dat die Gees die wyse is waarop Israels (jod in die hede vernuwend en bevrydend met ons wil omgaan. In die Gees gaan Israels Ciod wat in Jesus Christus Hom. self as (jod bewys het, met ons om. Die hermeneutiese krisis word so trinitaries opgelos.

Hierdie trinitariese oplossing. waardeur die H.S. as oorlewering van wat Israel met sy Bondgenoot-God ervaar het. vir ons aktueel word, is m.i. nie alleen kunsmatig nie. maar verberg die kiem van die Barthianisme. Die bybel is nie die Woord van God nie. maar word dit hier en nou onder die werking van die Heilige Gees. So ongemerk is van dic ou inspirasieleer afskeid geneem en die werk van die H. Gees verskuif van die ontstan of oorsprong van die tradisie na die ontranger daarvan. Deur die werking van die Heilige Gees word die Israelitiese oorlewering eers vir ons aktueel. Ons het dan eintlik te doen met in mensewoord wat die Woord van God word deur die subjektiewe aanvaarding daarvan onder die werking van die Heilige Gees. Die klem val nou op die ontvangers van die tradisie. gedrywe deur die Heilige Gees. Deur die ervaring van Israel se onimoeting met lsrael se God moet ons blykbaar so tot die ontmoeting van onse (iod kom! Hartvelt bou (in a.w.) op hierdie gedagte voort. Met sorg wys hy op die probleme rondom die H.S. wat daarop dui dat dit van menslike oorsprong is. Hy suggereer dat die H.S. nie in alle dele betroubaar is nie en sề dan (in verband met art. V N.(i.B.): ..Het is de Heilige (jeest zelf. dat wil zeggen: God aan-het-werk-onder ons. die er ons toe brengt het getuigenis der Schrift te aanvaarden. Waar hier met nadruk gesproken wordt over het .geloven' ligt het voor de hand dit op te vatten in de zin van het geloof-om-zalig-te worden. de verbondenheid met-God-in-Jezus Christus. Het alles waarop dit geloven is gericht is kennelijk niet kwantitatief beloeld in de zin van: de bybel-van de-eerste-lot-de-laaste bladzijde maar de schrift in haar centrale boodschap. Het getuigenis van de $\mathrm{H}$. (ieest kan men daarom nimmer losmaken van de zaak zelf" (a.w. p. 56). Die getuienis van die Heilige (iees slaan dus op die aanvaarding van die sentrale boodskap - dit sou dan die sin van art. 5 N.G.B. wees. Maar die klaarblyklike sin van art. 5 se .alles" slaan tog op wat in die Heilige Skrif vervat is. en dit dui geensins op in sentrale boodskap alleen nie.

Die vraag na die formele (ohpehtieuc) gesag van die Skrif bly vir Hartvelt ook dringend. Die meganiese en organiese inspirasie-teoriec moet egter afgewys worl. Die ekrywers is nie instrumente van die 
H. (jees nie (a.w. p. 62). Tog is die bybel 'n besondere bock: dit is Theopneustos - die woord inspirasie moet nie gebruik word nie (a.w. p. 63). ..Déze schrift die geheel en al getuigenis is, menselijke getuigenis, waarvan de Here God zich bedient. Dit menselijke getuigenis karakter der schrift komt niet in mindering op de theopneustie maar is de modus ervan", d.w.s. die bybel is 'n boek deur mense, van God geroep, geskrywe. Hulle is in besondere diens en nie van hulle mens. heid beroof nie. . Maar in deze menselijkheid door God in dienst genomen .... In deze dienst is hun woord .goed voor' het woord van God, in wat ze spraken en schrijven" (a.w. p. 71). Die ...ingee" van 2 Tim. 3:16 is slegs terloops en spreek nie oor die ontstaan van die Skrif nie. wel oor wat dit uitrig. doen. werk (vgl. a.w. p. 63 e.v.). God is wel met die ontstaan van die Skrif gemoeid, maar hoe weet ons nie (a.w.. p. 65). Die Skrif is dan wel betroubaar, maar in heel besondere sin: „.De betrouwbaarheid der Schrift is gegeven met haar centrale inhoud: God-in-Jezus-Christus" (a.w. p. 73). M.a.w.. so lyk dit vir my, eers moet uitgemaak word of en hoe dié saak ter sprake kom, voordat die betroubaarheid vasstaan. Hoewel Hartvelt probeer om nog 'n soort inspirasicleer na vore te bring. reken hy net soos Ktittert af met die ou inspirasicgedagte t.o.v. die ontstaan van die H.S. en is die enigste wat dui op inspirasie volgens sy opvatting, dat die menslike getuienis . goed voor" die Woord van God is. Hoe dit ..goed voor" is, bly "n subjektiewe saak - eers as dit aanvaar word as Woord van God deur die werking van die Heilige Gees.

Kuitert is bewus van die gevaar van relatiwiteit wat so t.o.v. dic Christelike waarheid ontstaan, en wil dit afweer, maar erken „wij hebben voor déze poging wel enige armslag nodig ..." (De Realiteit van het geloof p. 168). Die historisiteit van die waarheid hef nie dic vastheid, betroubaarheid van die waarheid op nie. Maar die vastheid van die waarheid mag ook nie in die tydloosheid daarvan gesoek word nie. Die historiese karakter van die waarheid moet behou word sonder dat daar 'n vermindering van die vastheid kom.

Die vastheid moet gesoek word in die historiese kontinuteit. God se selfopenbaring voltrek hom in die omgang. d.w.s. histories. Dit impliseer weer historiese respons, d.w.s. toe-eiening. Deur God se openbaring word mense opgeroep om die geloof in lsrael se God in sy Messias weer te gee. In die respons word dus wat as waarheid in die omgang onderhou word, geformuleer. Maar daar is kontinuiteit in hierdie formuleringe. Die agtergrond van die kontinuiteit lê in die God wie se kennis in die tradisie oorgelewer word. Hy is kontinuiteit $\mathrm{Hy}$ is deur die eeue dieselfue. Daarom is daar in alle geloofsuitspraks wat uit die omgang met hierdie God spruit naas diskontinuiteit ook kontinuiteit. Die betroubaarheid. die waarheidsaspek van die tradisie is dan gelë̈ in hierdie kontinuiteit. Alleen op dié wyse bly die betroubaarheid, die vastheid van die Christelike leer 'n saak van geloof i.p.v. redenering. M.a.w. hier word net op 'n ander wyse tot die slotsom van Hartvelt gekon - net die sentrale inhoud van die Skrif, vervat in die kontinuiteit, is .goed voor" God se woord. Die sack moet uit die historiese klankbodem gelig word. 


\section{SI () I}

Deur die antimetafisiese benadering van die teologie beweeg die skool van Kuitert in dieselfue koers as die nuwe teologie. Die natuurwetenskap het norm geword - ten spyte van ontkennings - in die benadering van die Skrif. 'n Nuwe Hermeneutiek moet die wetenskap terwille wees. Die weg is berei vir 'n nuwe Skrifbeskouing en Skrifverklaring wat aansluit by die nuwe teologie. Daar word deur dié skool dan ook al hoe meer teruggeval op die eksistensialistiese teologiese terme. Saam met die terminologie word die eksistensialistiese gedagtegang ingevoer en alhoemeer as deel van die gereformeerde gedagtegang ingeloods. Die revisielegende waalvan Kuyper spreek is nie meer in legende nie. maar beginsel vir hierdie teoloe t.o.v. die belydenisskrifte. Ook in die nuwe teologie soos beoefen deur die geref. teoloc vanuit die V.lI. en Kampen het die mens met sy kritiese rede die sentrum geword. Dit het ook ' $n$ verskuiwing in die Kerkreg gebring. Ek noem net prof. Plomp se versigtige afbraak van die gedagte dal die bestaan van in skriftuurlike kerkregeringstelsel nog moontlik is en sy propagering van 'n biskoplike stelsel van kerkregering.

Ek meen dat uit wat gesê is dit duidelik geword het dat daar in koerswysiging in die (jeref. Kerke in Nederland gekom het. Die krisis wat ons sinode van 1967. met betrekking tot ons verhouding tot dié kerke. nog wou afwend deur te verklaar dat daar nog net van .,teologiese diskussies" sprake is in die Nederlandse Geref. Kerke en daarom geen ondersoek na 'n koerswysiging noodsaak nie, het nou geblyk 'n stukkic volstruispolitiek te wees. Want nie alleen propageer Kuitert en sy skool die nuwe teologie soos deur hulle beoefen lankal openlik nie. dit is tans geweltig deur die jongste sinode (L.unteren 1967) van die Kerke. Die sinole het juis die leerbeslissing van Assen 1926 herroep om hierdie teologie 'n wellige plek te gee, soos blyk uit die verantwoording wat dié sinole oor die beslissing gepubliseer het (vgl. daaroor ..Assen 1926" o.d. p.p. Il en 20 waar die kom. Ad hoc die rede gee vir die aandrang om in onverwylde beslissing. vgl. ook [)r. J. Schelhaas: I e Val van Assen).

Vir die beoefening van gereformeerde teologie in S.A. kon nou werklik dic vraag na vore in hoever ons hierdie ..Nuwe Teologie" soos beoefen deur gemelde gereformeerde teoloe nog ..gereformeerd" kan noem.

Bloemfontein. Mei 1968.

G. P. I. van der I inde.

(ielewer voor (i. T. V. Realdersburg. 